\begin{abstract}
Submitted:
16.11.2020

Accepted:

27.01.2021

Published:

07.06.2021

\section{Reference values for the cross-sectional area of the normal sciatic nerve using high-resolution ultrasonography}

\author{
Kunwar Pal Singh, Prabhjot Singh, Kamlesh Gupta \\ Radiodiagnosis, SGRD University of Health Sciences, India \\ Correspondence: Kunwar Pal Singh, e-mail:kpsdhami@hotmail.com
}

DOI: $10.15557 / \mathrm{JoU} .2021 .0018$

Keywords

sciatic nerve, cross-sectional area,

high-resolution ultrasonography

Abstract

Aim: High-resolution ultrasonography is a new and promising technique to evaluate peripheral and spinal nerves. Its validity as a diagnostic tool in neurological diseases has been demonstrated in adults. The aims of study were to establish the reference values for the cross-sectional area of the normal sciatic nerve on high-resolution ultrasonography, and to determine the relationship between the cross-sectional area of the normal sciatic nerve and the subjects' age, gender, height (in $\mathrm{cm}$ ), weight (in $\mathrm{kg}$ ), and body mass index. Material and methods: Two hundred subjects of both genders and above 18 years of age were studied with high-resolution ultrasonography. The subjects had no history of peripheral neuropathy or trauma to the lower limb. The cross-sectional areas of the normal sciatic nerves were obtained at two different levels in both lower limbs. The mean cross-sectional areas of the sciatic nerves were measured at two different levels, one located at $1 \mathrm{~cm}$ above the bifurcation of the sciatic nerve into the tibial and common peroneal nerves, and the other $4 \mathrm{~cm}$ above the bifurcation of the sciatic nerve into the tibial and common peroneal nerves. Results: A positive correlation of the mean cross-sectional area was established with height, weight, and body mass index. Women had smaller cross-sectional areas of the normal sciatic nerves than men at both measuring sites. No significant relationship was established with the age of the subjects. Conclusions: The established reference values of the cross-sectional area of the sciatic nerve can facilitate the analysis of pathological nerve conditions.
\end{abstract}

\section{Introduction}

High-resolution ultrasonography (HRUS) is a new tool to investigate the peripheral and spinal nerves ${ }^{(1)}$. It serves as a diagnostic tool in neurological diseases in adults ${ }^{(2)}$. The introduction of US probes with high frequencies (greater than $12-15 \mathrm{MHz}$ ) has played a significant role in the ultrasound diagnostics of the peripheral nerves ${ }^{(3)}$.

Normal peripheral nerves have a typical sonographic appearance, demonstrating multiple hypoechoic bands representing fascicular bundles surrounded by a hyperechoic rim ${ }^{(1)}$. High-resolution ultrasonography provides a cost-efficient and accurate imaging modality in the diagnosis of peripheral nerve lesions ${ }^{(4)}$. The variability in crosssectional area (CSA) measurements is helpful in investigating pathologies of the peripheral nerves ${ }^{(3)}$.
The cross-sectional area (CSA) tends to be symmetrical in both lower limbs, and it is larger in the lower limb motor nerves than in the sensory nerves at similar sites ${ }^{(5)}$. Recent imaging techniques allow for the assessment of anatomical characteristics of extremities exposed to a traumatic injury, greatly enhancing the quality of patient care, and help in optimizing clinical outcomes $^{(6)}$.

The examination of the peripheral nerves by US imaging is non-invasive and easily tolerated by patients ${ }^{(7)}$. High-resolution ultrasonography is helpful in assessing the morphology of the peripheral nerves ${ }^{(5)}$. It has added to the diagnosis and treatment decisions among mononeuropathies, and assisted in the diagnosis of peripheral nerve tumors, hereditary neuropathy, and dysimmune neuropathy ${ }^{(8,9)}$. 


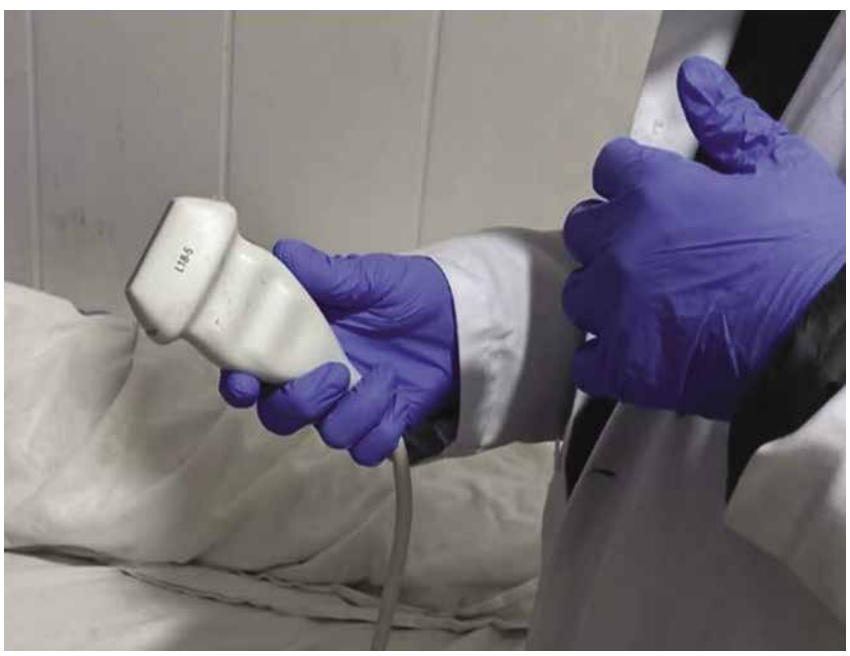

Fig. 1. A linear transducer (Philips Affinity 50) with a frequency of $5-18 \mathrm{MHz}$

High-resolution ultrasonography can detect changes in the peripheral nerves caused by a number of disease processes including trauma, infection, inflammation, and benign and malignant tumors, in a cost-effective manner ${ }^{(10)}$.

The method is able to detect acute and chronic changes in the nerves caused by compression neuropathies ${ }^{(11)}$. Chronic nerve compression causes disruption of the paranodal junctions and axonal domains required for proper peripheral nerve function ${ }^{(12)}$.

Ultrasound evaluation can lead to early diagnosis of nerve injuries and hence facilitate prompt treatment ${ }^{(13)}$. The ability of the clinical evaluation and electrodiagnostic studies to determine the extent of nerve damage within the first 6 weeks after trauma is limited ${ }^{(14)}$. The availability of CT and MR neurography is limited and the associated costs are high ${ }^{(15)}$. On the other hand, ultrasonography is a cost-efficient, portable, and dynamic modality ${ }^{(15)}$.
Not many studies have been done in the past to determine the reference values of the cross-sectional area of the normal sciatic nerve. Thus, the present study seeks to obtain high-resolution ultrasonography images of the normal sciatic nerve, and on that basus assess possible relationships between the cross-sectional area and the patient's age, height, weight, and body mass index $(\mathrm{BMI})^{(1)}$.

\section{Material and methods}

Two hundred subjects of both genders, above 18 years of age, and without any history of peripheral neuropathy or trauma to the lower limb, were studied by high-resolution ultrasonography.

\section{Patient inclusion criteria}

Subjects with no history of peripheral neuropathy or trauma to the lower limb.

\section{Exclusion criteria}

All patients with peripheral neuropathy due to:

- trauma involving a lower extremity and/or lumbar plexus injury,

- hypothyroidism,

- diabetes mellitus,

- pregnancy,

- alcohol,

- drug-induced.

After taking the informed written consent from each patient, detailed clinical history was recorded, and general physical and local examination was carried out, and high-resolution ultrasonography of the sciatic nerve was performed in both lower limbs.

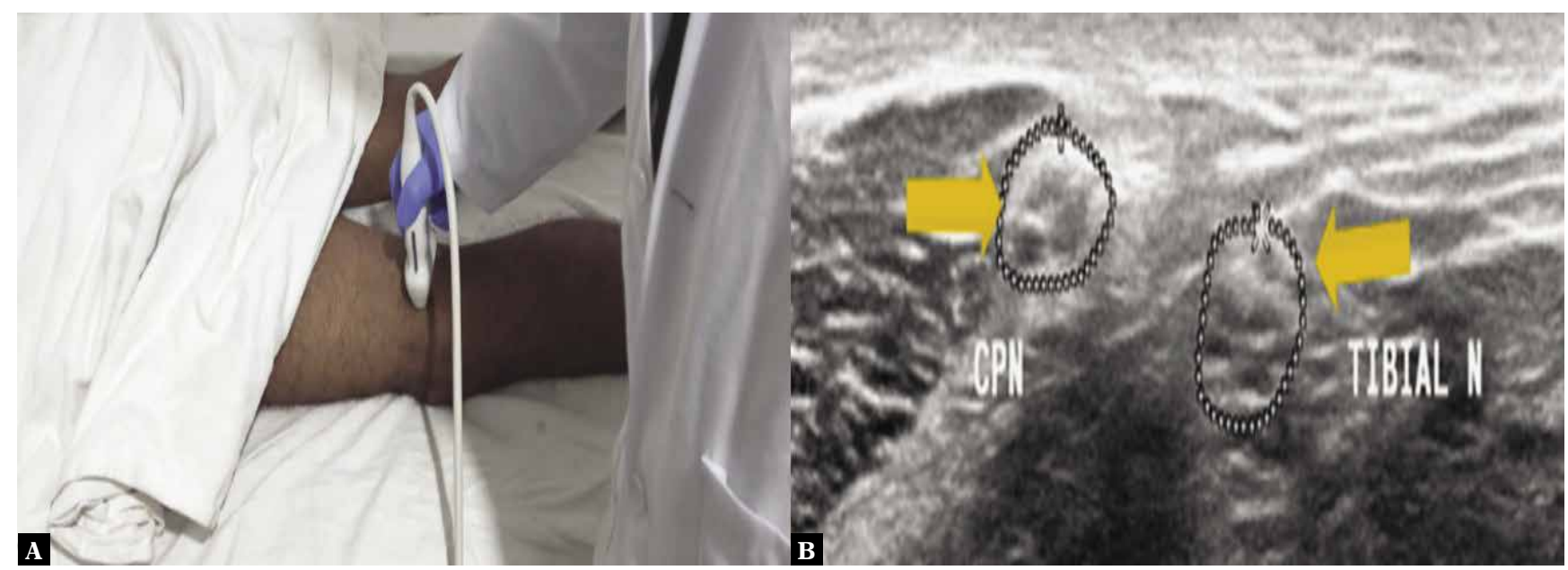

Fig. 2. A. With the subject lying in prone position, the transducer is kept perpendicular to the popliteal fossa. B. High-resolution ultrasonography image at the same level showing two branches of the sciatic nerve (yellow arrows) i.e. tibial nerve medially and common peroneal nerve (CPN) laterally ( $N$ - nerve) 


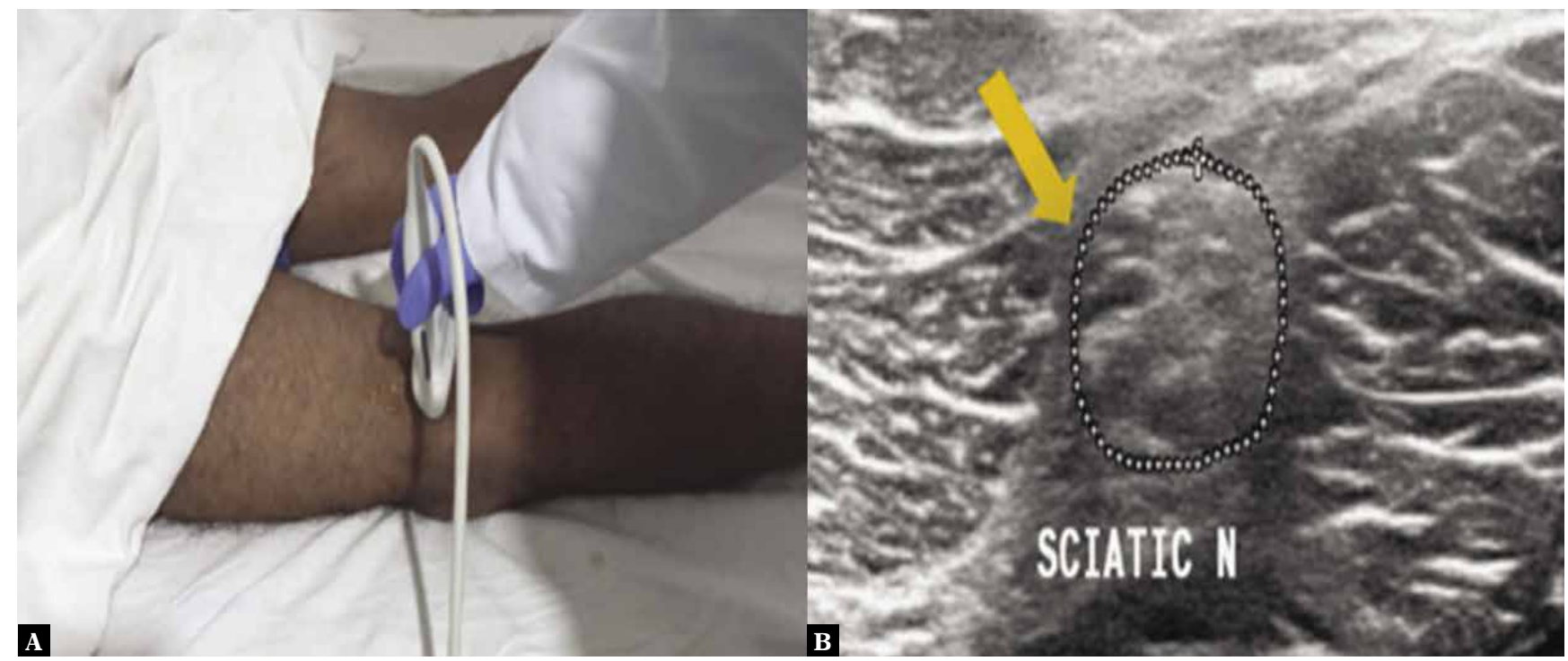

Fig. 3. A. The transducer is kept $1 \mathrm{~cm}$ proximal to the site shown in Fig. 2. B. High-resolution ultrasonography image at the same level showing the sciatic nerve (yellow arrow) formed from its two branches i.e. the tibial and common peroneal nerves ( $N-n e r v e)$

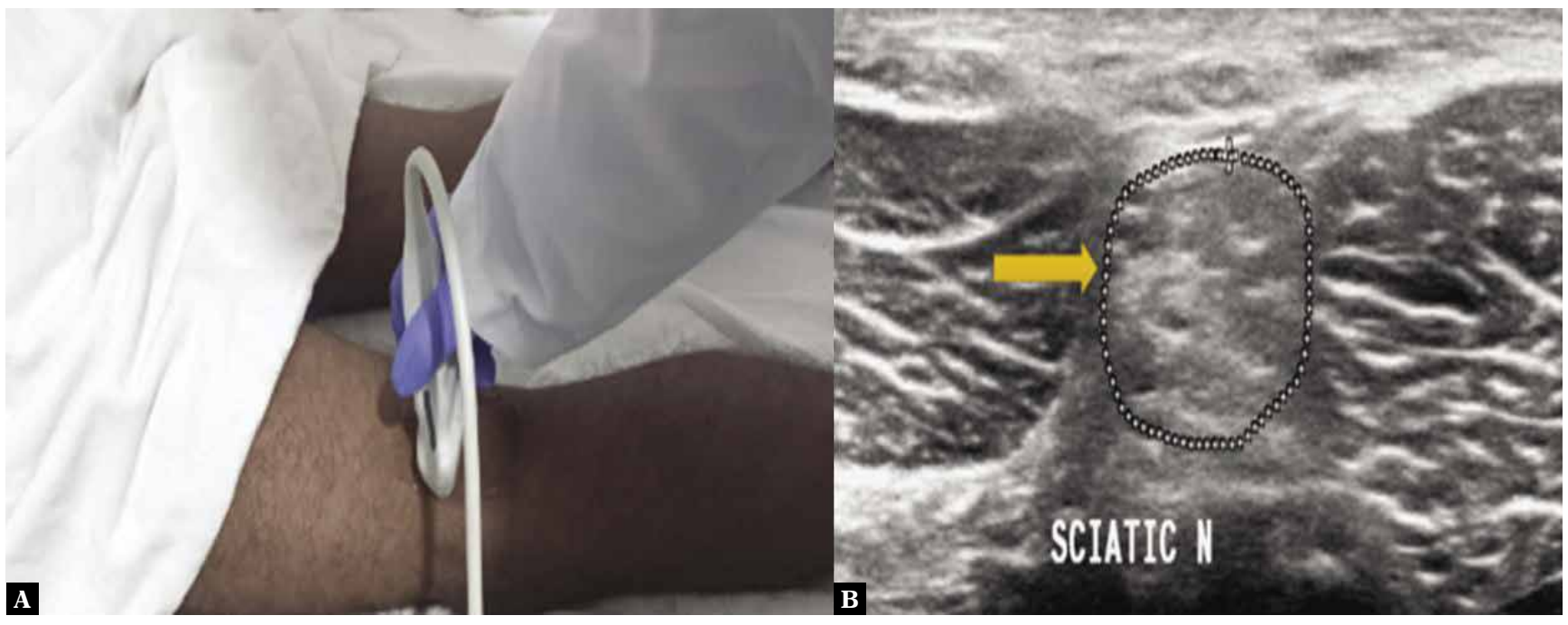

Fig. 4. A. The transducer is kept $4 \mathrm{~cm}$ above the bifurcation of the sciatic nerve into the tibial and common peroneal nerves. B. High-resolution ultrasonography image showing measurement of the cross-sectional area of the normal sciatic nerve (yellow arrow) at this level ( $N$-nerve)

\section{Ultrasonography technique}

High-resolution sonography was performed using Philips Affiniti 50 unit with a linear transducer with a frequency of 5-18 MHz (Fig. 1). The depth, gain, and dynamic range were adjusted appropriately for the optimal differentiation between the nerves and other soft tissue structures. The ultrasound images were obtained by placing the transducer perpendicular to the normal sciatic nerve at two levels on both lower limbs. The images were obtained with the subject in prone position. The pressure of the transducer on the skin was kept to a minimum to reduce as far as possible the deformation of underlying structures. A few studies have demonstrated the use of standard imaging as well as write-zoom magnification methods for the measurement of the CSA. In the present study, we used only standard imaging.
The cross-sectional areas of the sciatic nerve were measured at the following locations. Level I was located $1 \mathrm{~cm}$ above the bifurcation of the sciatic nerve into the tibial and common peroneal nerves. Level II was located $4 \mathrm{~cm}$ above the bifurcation of the sciatic nerve into the tibial and common peroneal nerves (Fig. 2, Fig. 3, Fig. 4). At each site, the cross-sectional area of the sciatic nerve was obtained by tracing the nerve just inside its hyperechoic rim. Three measurements were taken at each site, with the transducer repositioned. The mean value was used for each level (Fig. 5, Fig. 6, Fig. 7, Fig. 8, Fig. 9, Fig. 10, Fig. 11, Fig. 12).

The age, gender, height, weight and body mass index obtained for each subject were documented, and then correlation coefficients were calculated by statistically correlating these parameters with the cross-sectional area of the sciatic nerve at both levels. 


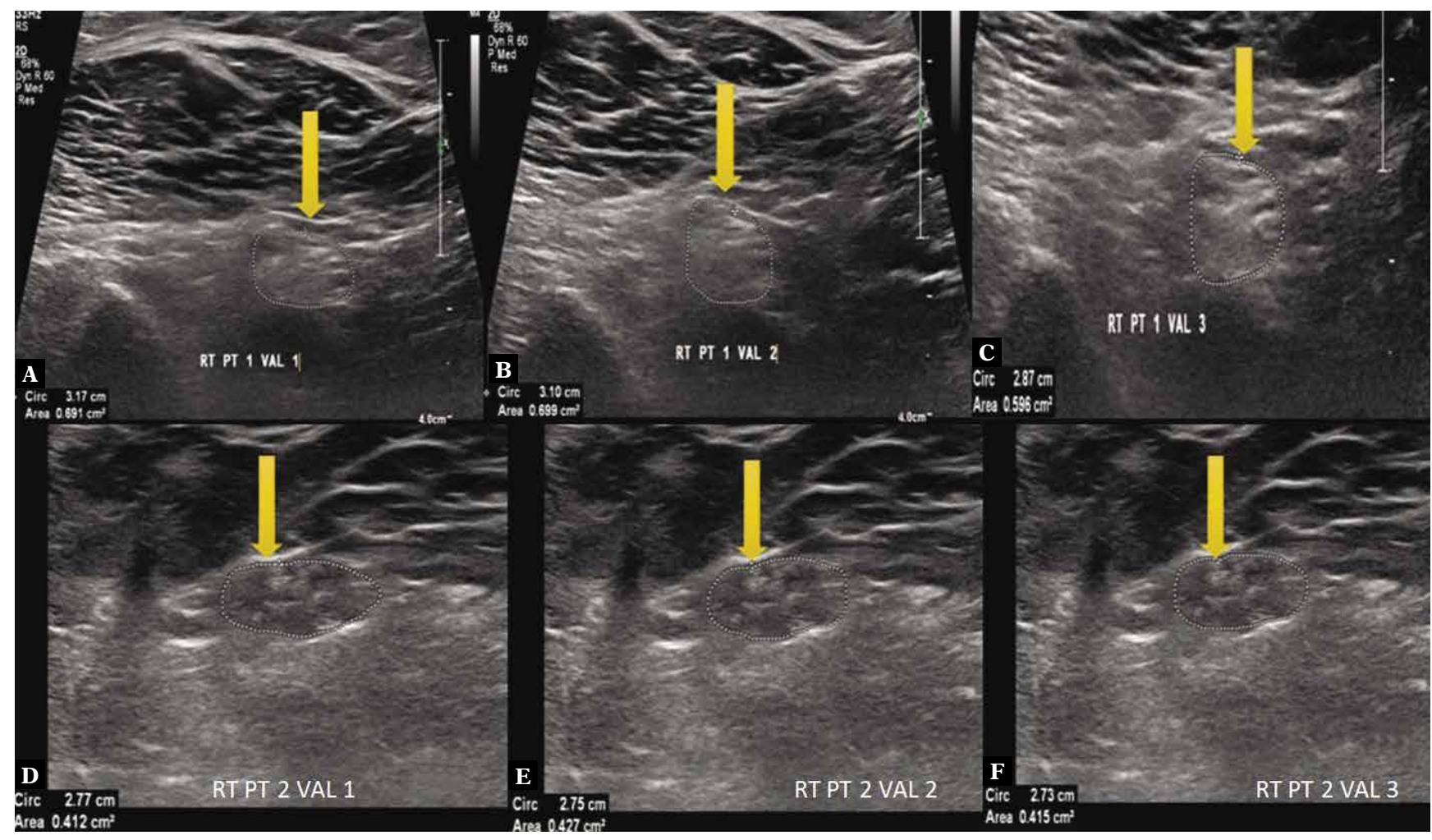

Fig. 5. High-resolution ultrasonography of the normal sciatic nerve at levels I (images $\mathbf{A}, \mathbf{B}, \mathbf{C}$ ) and II (images $\mathbf{D}, \mathbf{E}, \mathbf{F}$ ) in the right lower limb in a 64-year-old male weighing $83 \mathrm{~kg}$, with a height of $180 \mathrm{~cm}$, and BMI of 25.6. The mean cross-sectional area measured at level I was $0.662 \mathrm{~cm}^{2}$, and at level II it was $0.418 \mathrm{~cm}^{2}$ (RT - right, LT - left, PT - point, VAL - value, yellow arrow - sciatic nerve)

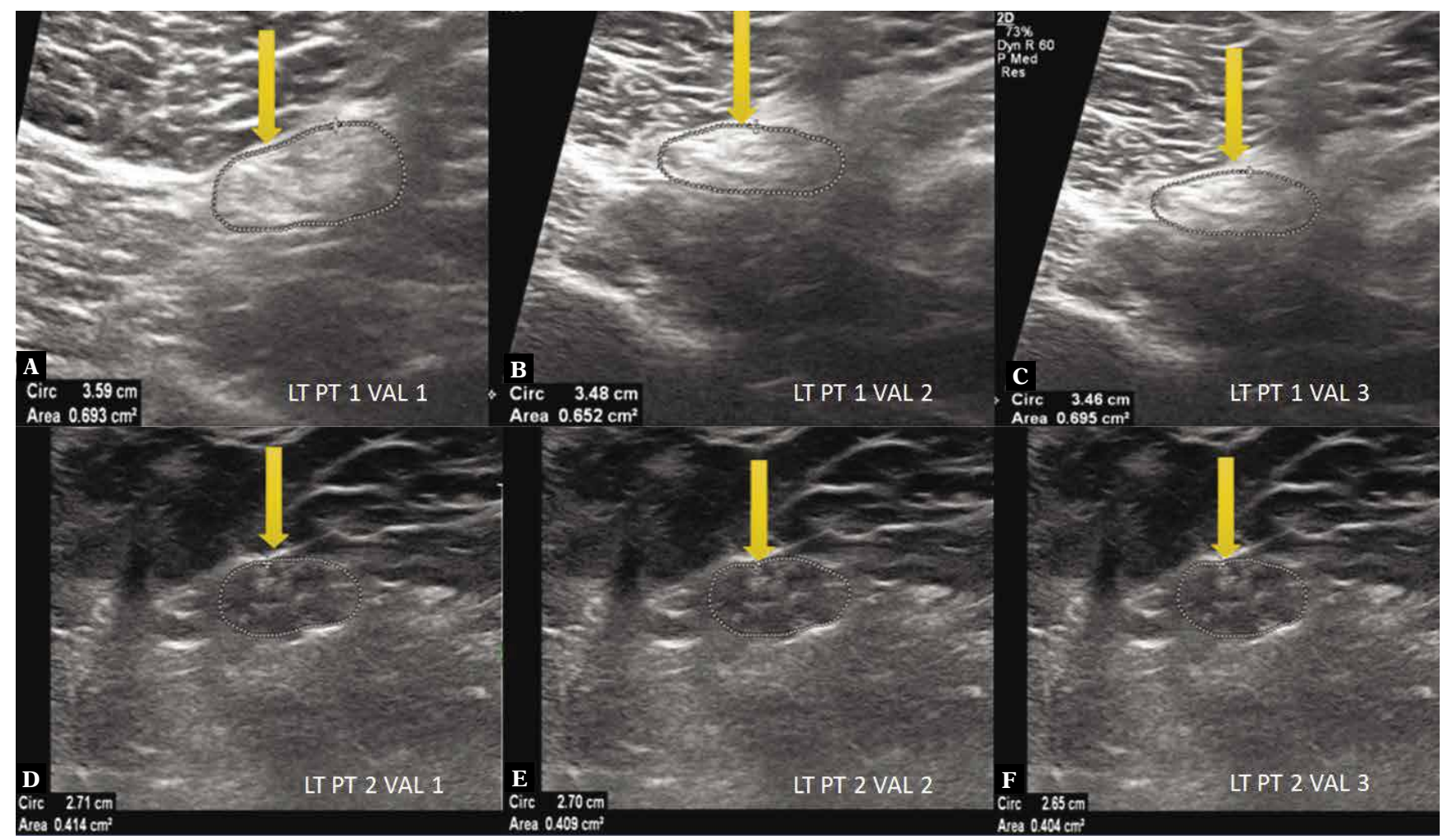

Fig. 6. High-resolution ultrasonography of the normal sciatic nerve at levels I (images $\mathbf{A}, \mathbf{B}, \mathbf{C}$ ) and II (images $\mathbf{D}, \mathbf{E}, \mathbf{F})$ in the left lower limb in a 64-year-old male weighing $83 \mathrm{~kg}$, with a height of $180 \mathrm{~cm}$, and BMI of 25.6. The mean cross-sectional area measured at level I was $0.680 \mathrm{~cm}^{2}$, and at level II it was $0.409 \mathrm{~cm}^{2}$ (RT - right, LT - left, PT - point, VAL - value, yellow arrow - sciatic nerve) 


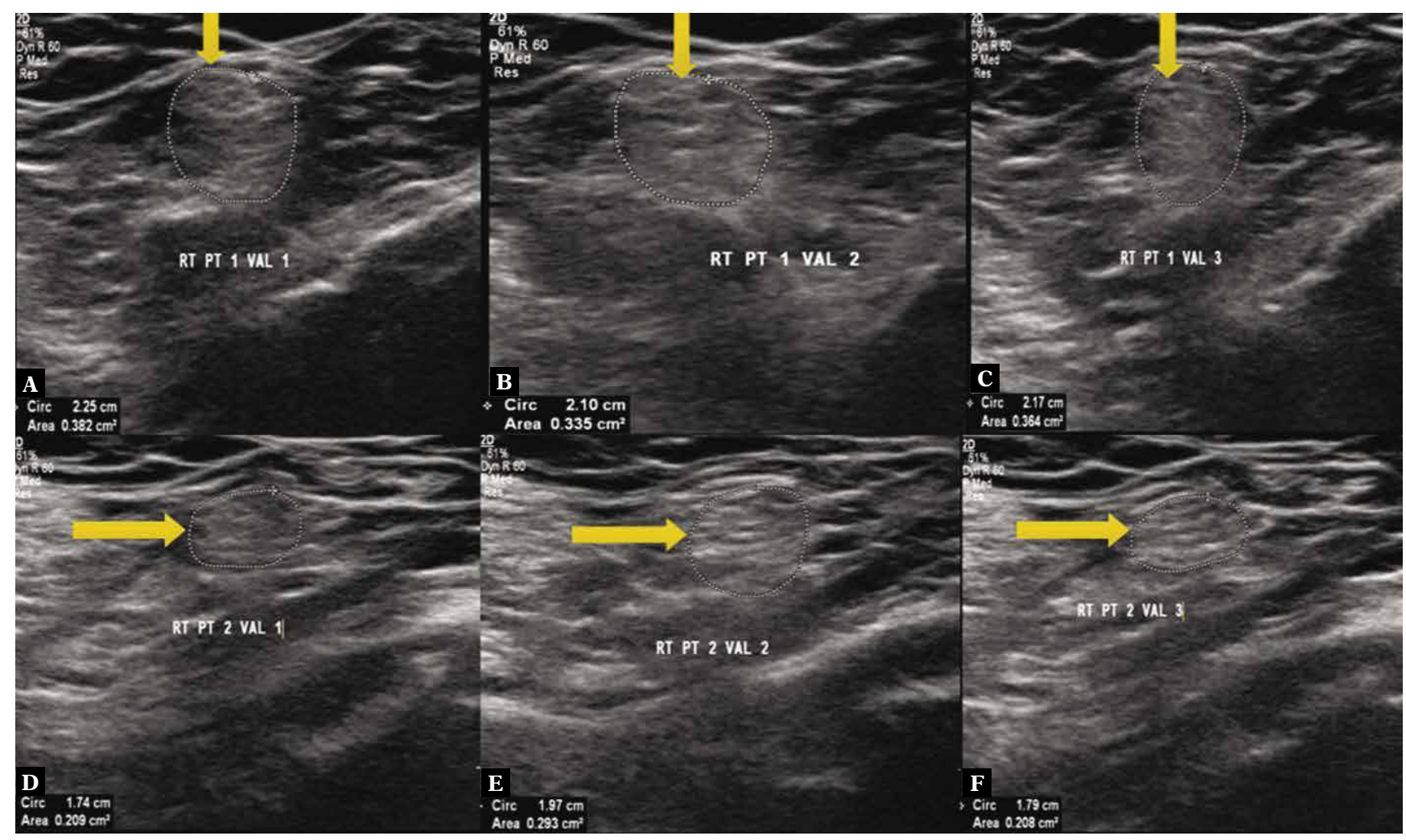

Fig. 7. High-resolution ultrasonography of the normal sciatic nerve at levels I (images $\mathbf{A}, \mathbf{B}, \mathbf{C}$ ) and II (images $\mathbf{D}, \mathbf{E}, \mathbf{F})$ in the right lower limb in a 61-year-old male weighing $55 \mathrm{~kg}$, with a height of $154 \mathrm{~cm}$, and BMI of 23.2. The mean cross-sectional area measured at level I was $0.360 \mathrm{~cm}^{2}$, and at level II it was $0.236 \mathrm{~cm}^{2}$ (RT - right, LT - left, PT - point, VAL - value, yellow arrow - sciatic nerve)

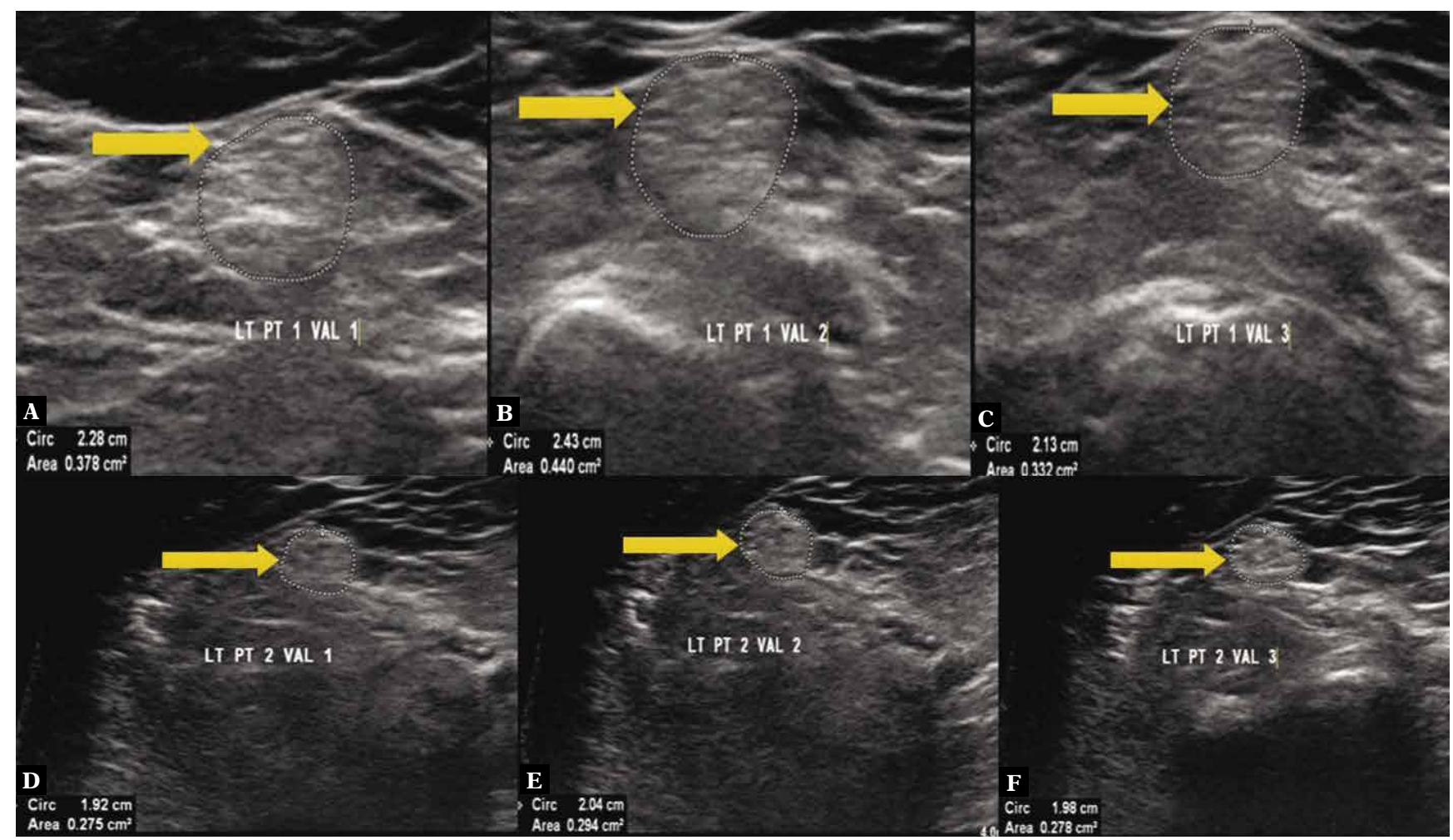

Fig. 8. High-resolution ultrasonography of the normal sciatic nerve at levels I (images $\mathbf{A}, \mathbf{B}, \mathbf{C}$ ) and II (images $\mathbf{D}, \mathbf{E}, \mathbf{F})$ in the left lower limb in a 61-year-old male weighing $55 \mathrm{~kg}$, with a height of $154 \mathrm{~cm}$, and BMI of 23.2. The mean cross-sectional area measured at level I was $0.383 \mathrm{~cm}^{2}$, and at level II it was $0.282 \mathrm{~cm}^{2}$ (RT - right, LT - left, PT - point, VAL - value, yellow arrow - sciatic nerve) 


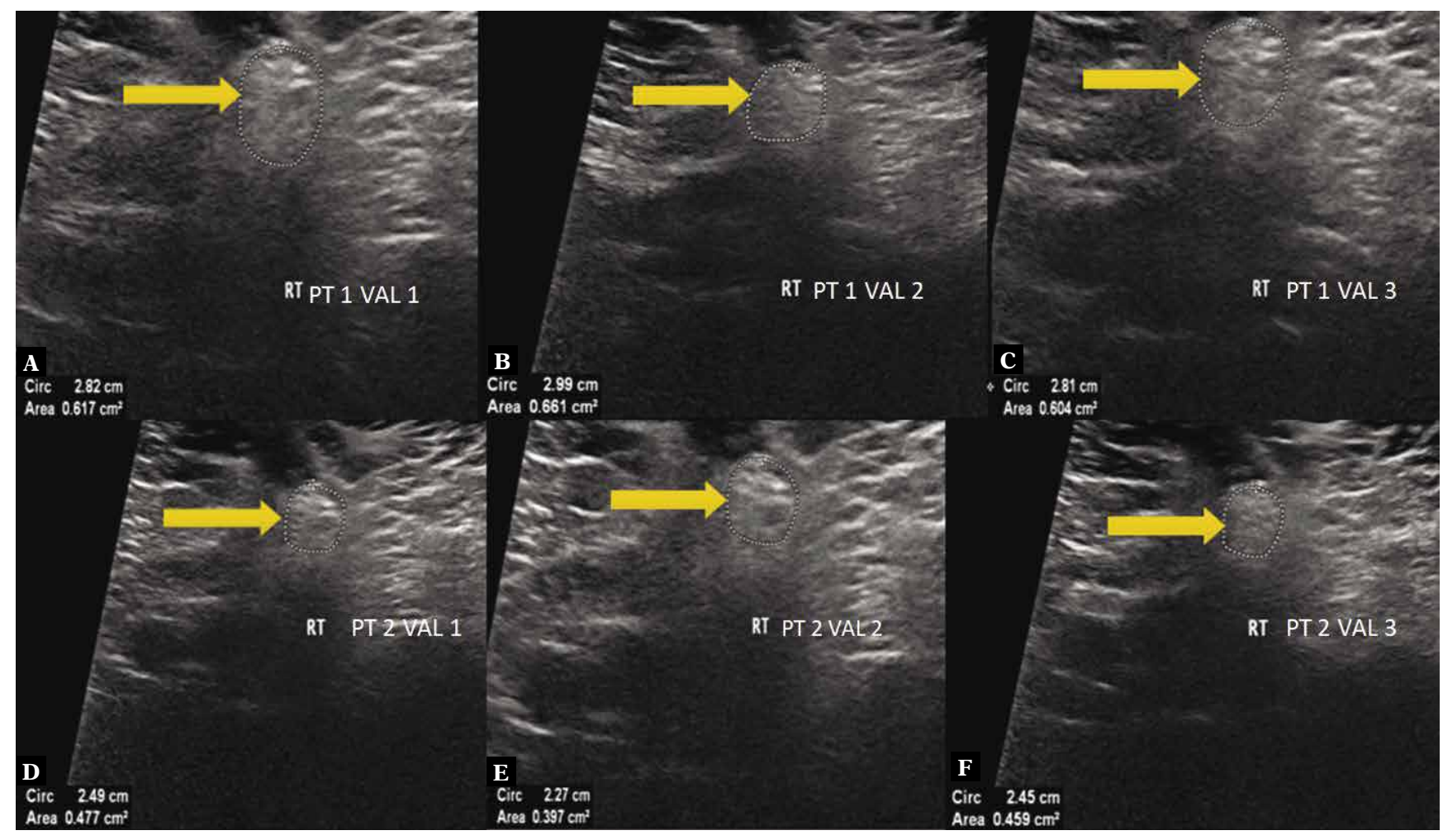

Fig. 9. High-resolution ultrasonography of the normal sciatic nerve at levels I (images $\mathbf{A}, \mathbf{B}, \mathbf{C}$ ) and II (images $\mathbf{D}, \mathbf{E}, \mathbf{F}$ ) in the right lower limb in a 37-year-old male weighing $86 \mathrm{~kg}$, with a height of $184 \mathrm{~cm}$, and BMI of 25.4. The mean cross-sectional area measured at level I was $0.627 \mathrm{~cm}^{2}$, and at level II it was $0.444 \mathrm{~cm}^{2}$ (RT - right, LT - left, PT - point, VAL - value, yellow arrow - sciatic nerve)

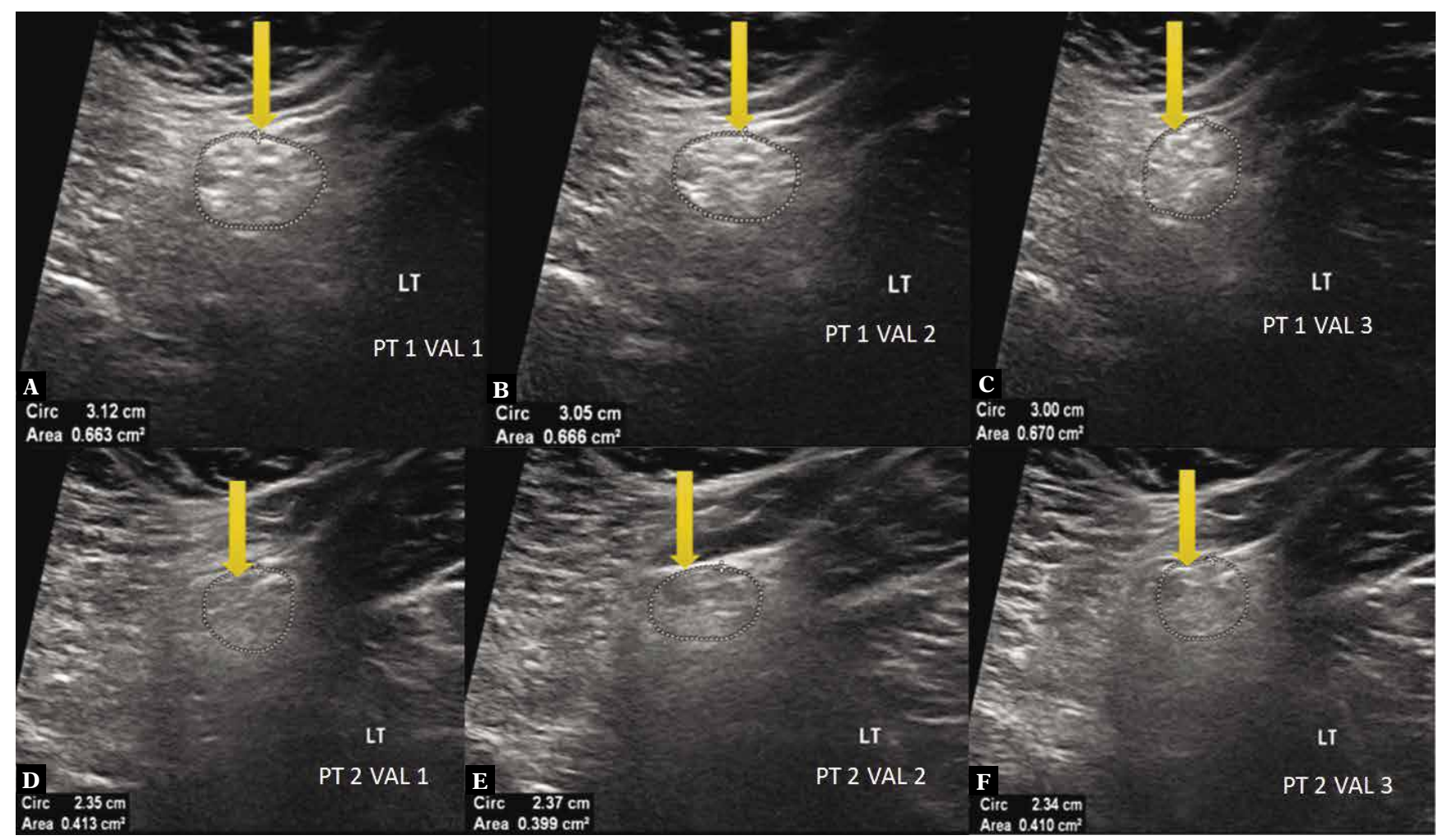

Fig. 10. High-resolution ultrasonography of the normal sciatic nerve at levels I (images $\mathbf{A}, \mathbf{B}, \mathbf{C}$ ) and II (images $\mathbf{D}, \mathbf{E}, \mathbf{F})$ in the left lower limb in a 37-year-old male weighing $86 \mathrm{~kg}$, with a height of $184 \mathrm{~cm}$, and BMI of 25.4. The mean cross-sectional area measured at level I was $0.666 \mathrm{~cm}^{2}$, and at level II it was $0.407 \mathrm{~cm}^{2}$ (RT-right, LT - left, PT-point, VAL-value,yellow arrow - sciatic nerve) 


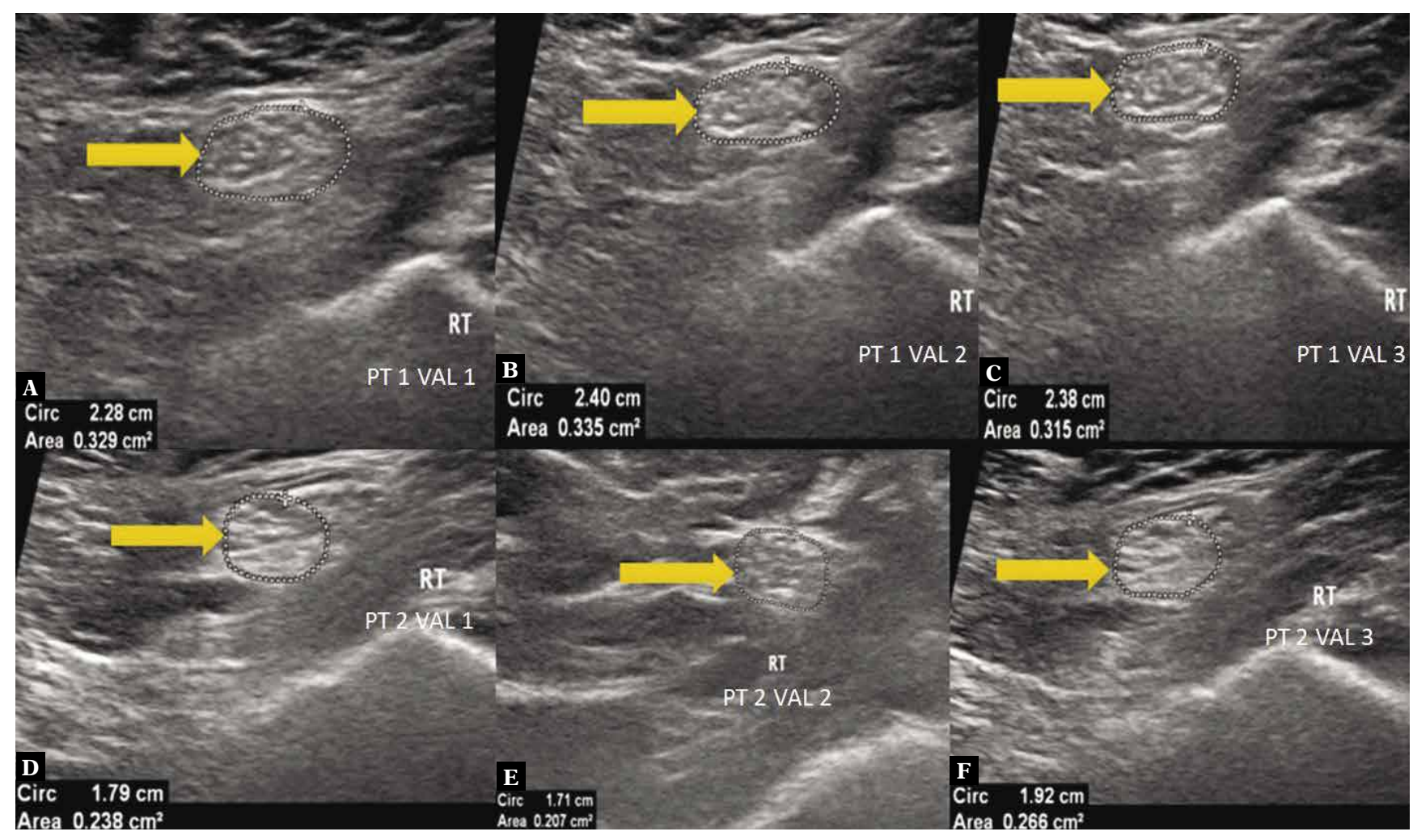

Fig. 11. High-resolution ultrasonography of the normal sciatic nerve at levels I (images $\mathbf{A}, \mathbf{B}, \mathbf{C})$ and II (images $\mathbf{D}, \mathbf{E}, \mathbf{F})$ in the right lower limb in a 42-year-old female weighing $52 \mathrm{~kg}$, with a height of $155 \mathrm{~cm}$, and BMI of 21.6. The mean cross-sectional area measured at level I was $0.326 \mathrm{~cm}^{2}$, and at level II it was $0.237 \mathrm{~cm}^{2}$ (RT - right, LT - left, PT - point, VAL - value, yellow arrow - sciatic nerve)

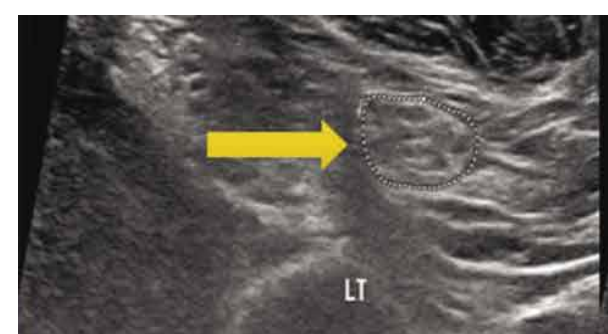

PT 1 VAL 1

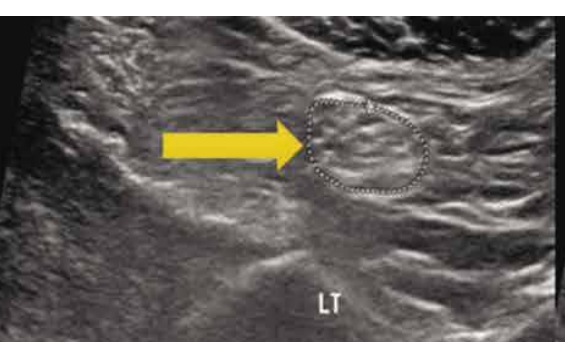

PT 1 VAL 2

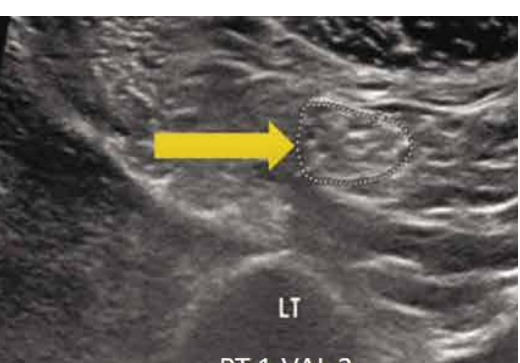

PT 1 VAL 3

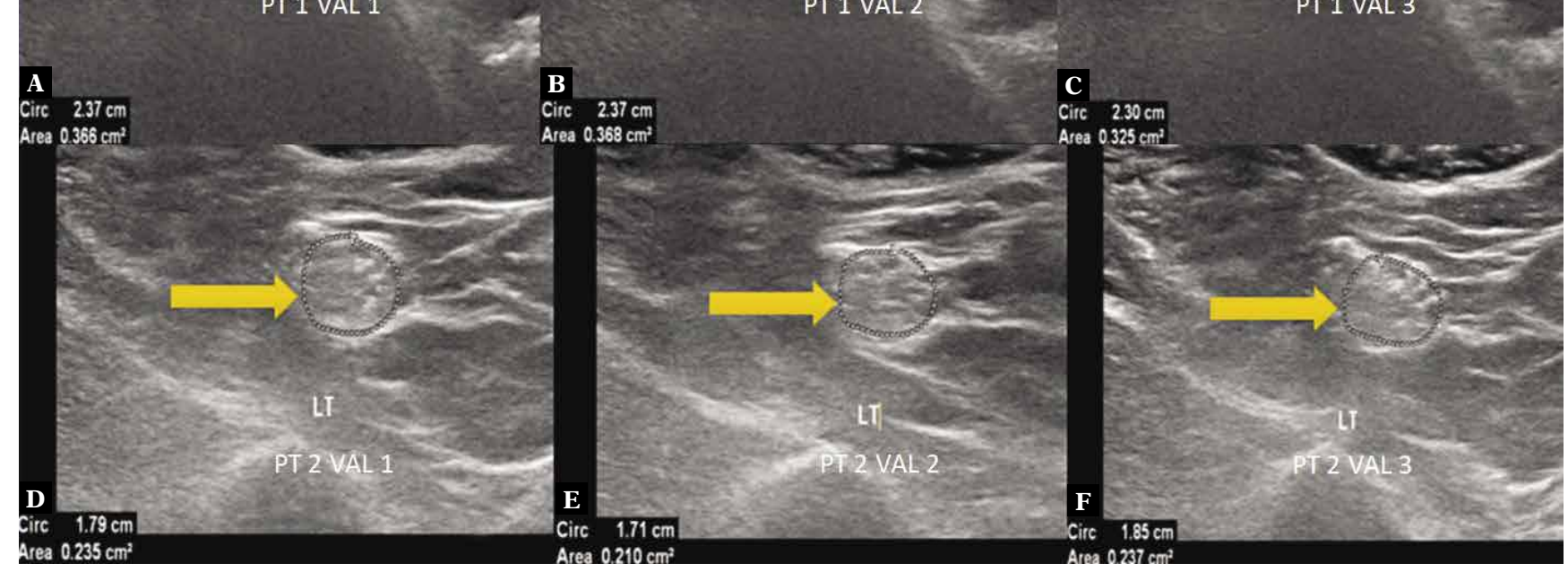

Fig. 12. High-resolution ultrasonography of the normal sciatic nerve at levels I (images $\mathbf{A}, \mathbf{B}, \mathbf{C}$ ) and II (images $\mathbf{D}, \mathbf{E}, \mathbf{F})$ in the left lower limb in a 42-year-old female weighing $52 \mathrm{~kg}$, with a height of $155 \mathrm{~cm}$, and BMI of 21.6. The mean cross-sectional area measured at level I was $0.353 \mathrm{~cm}^{2}$, and at level II it was $0.227 \mathrm{~cm}^{2}$ (RT - right, LT - left, PT - point, VAL - value, yellow arrow - sciatic nerve) 
Tab. 1. Cross-sectional area of the sciatic nerve at two levels and its relationship with gender

\begin{tabular}{|c|c|c|c|c|c|c|c|}
\hline \multirow{3}{*}{ Gender } & \multirow{3}{*}{ No. of cases } & \multicolumn{6}{|c|}{ Lower limb level 1 mean CSA ( $\mathrm{cm}^{2}$ ) } \\
\hline & & \multicolumn{2}{|c|}{ Right } & \multirow{2}{*}{$p$-value } & \multicolumn{2}{|c|}{$\begin{array}{r}\text { Left } \\
\end{array}$} & \multirow{2}{*}{$p$-value } \\
\hline & & Mean & SD & & Mean & SD & \\
\hline Male & 108 & 0.560 & 0.074 & \multirow{2}{*}{$\begin{array}{l}r=-0.631 \\
p=0.001\end{array}$} & 0.562 & 0.071 & \multirow{2}{*}{$\begin{array}{l}r=-0.641 \\
p=0.001\end{array}$} \\
\hline Female & 94 & 0.456 & 0.051 & & 0.458 & 0.051 & \\
\hline \multirow{3}{*}{ Gender } & \multirow{3}{*}{ No. of cases } & \multicolumn{6}{|c|}{ Lower limb level 2 mean CSA $\left(\mathrm{cm}^{2}\right)$} \\
\hline & & \multicolumn{2}{|c|}{ Right } & & \multicolumn{2}{|c|}{ Left } & \multirow{2}{*}{$p$-value } \\
\hline & & Mean & SD & $p$-value & Mean & SD & \\
\hline Male & 108 & 0.428 & 0.060 & \multirow{2}{*}{$\begin{array}{c}r=-0.594 \\
p=0.001\end{array}$} & 0.424 & 0.061 & \multirow{2}{*}{$\begin{array}{c}r=-0.556 \\
p=0.001\end{array}$} \\
\hline Female & 94 & 0.348 & 0.047 & & 0.351 & 0.046 & \\
\hline
\end{tabular}

Tab. 2. Cross-sectional area of the sciatic nerve at two levels and its relationship with age

\begin{tabular}{|c|c|c|c|c|c|c|c|}
\hline \multirow{3}{*}{ Age group (years) } & \multirow{3}{*}{ No. of cases } & \multicolumn{6}{|c|}{ Lower limb level 1 mean CSA ( $\left.\mathrm{cm}^{2}\right)$} \\
\hline & & \multicolumn{2}{|c|}{ Right } & \multirow{2}{*}{$p$-value } & \multicolumn{2}{|c|}{ Left } & \multirow{2}{*}{$p$-value } \\
\hline & & Mean & SD & & Mean & SD & \\
\hline $18-30$ & 43 & 0.501 & 0.062 & \multirow{3}{*}{$\begin{array}{l}r=0.121 \\
p=0.080\end{array}$} & 0.503 & 0.078 & \multirow{3}{*}{$\begin{array}{l}r=0.118 \\
p=0.070\end{array}$} \\
\hline $31-50$ & 82 & 0.512 & 0.055 & & 0.515 & 0.061 & \\
\hline$>50$ & 77 & 0.528 & 0.093 & & 0.532 & 0.092 & \\
\hline \multirow{3}{*}{ Age group (years) } & \multirow{3}{*}{ No. of cases } & \multicolumn{6}{|c|}{ Lower limb level 2 mean CSA ( $\left.\mathrm{cm}^{2}\right)$} \\
\hline & & \multicolumn{2}{|c|}{ Right } & \multirow{2}{*}{$p$-value } & \multicolumn{2}{|c|}{ Left } & \multirow{2}{*}{$p$-value } \\
\hline & & Mean & SD & & Mean & SD & \\
\hline $18-30$ & 43 & 0.388 & 0.056 & \multirow{3}{*}{$\begin{array}{l}r=0.167 \\
p=0.091\end{array}$} & 0.385 & 0.059 & \multirow{3}{*}{$\begin{array}{l}r=0.178 \\
p=0.098\end{array}$} \\
\hline $31-50$ & 82 & 0.396 & 0.041 & & 0.395 & 0.072 & \\
\hline$>50$ & 77 & 0.403 & 0.073 & & 0.403 & 0.071 & \\
\hline
\end{tabular}

Tab. 3. Cross-sectional area of the sciatic nerve at two levels and its relationship with height

\begin{tabular}{|c|c|c|c|c|c|c|c|}
\hline \multirow{3}{*}{ Height $(\mathrm{cm})$} & \multirow{3}{*}{ No. of cases } & \multicolumn{6}{|c|}{ Lower limb level 1 mean CSA $\left(\mathrm{cm}^{2}\right)$} \\
\hline & & \multicolumn{2}{|c|}{ Right } & \multirow{2}{*}{$p$-value } & \multicolumn{2}{|c|}{ Left } & \multirow{2}{*}{$p$-value } \\
\hline & & Mean & SD & & Mean & SD & \\
\hline$<165$ & 74 & 0.430 & 0.032 & \multirow{3}{*}{$\begin{array}{l}r=0.921 \\
p=0.001\end{array}$} & 0.434 & 0.032 & \multirow{3}{*}{$\begin{array}{l}r=0.847 \\
p=0.001\end{array}$} \\
\hline $166-175$ & 64 & 0.513 & 0.023 & & 0.513 & 0.025 & \\
\hline$>175$ & 64 & 0.605 & 0.055 & & 0.607 & 0.055 & \\
\hline \multirow{3}{*}{ Height $(\mathrm{cm})$} & \multirow{3}{*}{ No. of cases } & \multicolumn{6}{|c|}{ Lower limb level 2 mean CSA $\left(\mathrm{cm}^{2}\right)$} \\
\hline & & \multicolumn{2}{|c|}{ Right } & \multirow{2}{*}{$p$-value } & \multicolumn{2}{|c|}{ Left } & \multirow{2}{*}{$p$-value } \\
\hline & & Mean & SD & & Mean & SD & \\
\hline$<165$ & 74 & 0.322 & 0.032 & \multirow{3}{*}{$\begin{array}{l}r=0.926 \\
p=0.001\end{array}$} & 0.324 & 0.029 & \multirow{3}{*}{$\begin{array}{l}r=0.826 \\
p=0.001\end{array}$} \\
\hline $166-175$ & 64 & 0.404 & 0.030 & & 0.403 & 0.035 & \\
\hline$>175$ & 64 & 0.457 & 0.047 & & 0.453 & 0.046 & \\
\hline
\end{tabular}

\section{Statistical analysis}

The data was analyzed using SPSS 19.5 software. The $p$ value of less than 0.05 was considered statistically significant. An independent sample t-test was used to evaluate and interpret the data. The correlation of the cross-sectional area of the sciatic nerve with the subjects' age, gender, height, weight and BMI was done using Pearson's correlation analysis.

\section{Results}

The mean cross-sectional area of the normal sciatic nerves located $4 \mathrm{~cm}$ above the bifurcation of the sciatic nerve into the tibial and common peroneal nerves (Level I) was $0.512 \mathrm{~cm}^{2}$ in the right lower limb, and $0.514 \mathrm{~cm}^{2}$ in the left lower limb.

The mean cross-sectional area of the normal sciatic nerve $1 \mathrm{~cm}$ above the bifurcation of the sciatic nerve into the tibial and common peroneal nerves (Level II) was
$0.391 \mathrm{~cm}^{2}$ in the right lower limb and $0.390 \mathrm{~cm}^{2}$ in the left lower limb. Women had smaller cross-sectional areas of the normal sciatic nerves than men in both measuring sites (Tab. 1). However, no correlation was observed between the cross-sectional area and the age of the subjects $(p>0.05)$ (Tab. 2). The mean cross-sectional areas at two levels in both lower limbs showed a positive correlation $(p<0.05)$ with height, weight and body mass index, as calculated by Pearson's correlation analysis (Tab. 3, Tab. 4 and Tab. 5).

\section{Discussion}

The sciatic nerve is the thickest nerve and the largest branch of the sacral plexus. It has the root values of L4, L5, S1, S2, S3. It has two parts: tibial and common peroneal. The tibial part is formed by the ventral divisions, and the common peroneal part by the dorsal divisions of the anterior primary rami of L4, L5, S1, S2, S3 ${ }^{(16)}$. 
Tab. 4. Cross-sectional area of the sciatic nerve at two levels and its relationship with body weight

\begin{tabular}{|c|c|c|c|c|c|c|c|}
\hline \multirow{3}{*}{ Weight (kg) } & \multirow{3}{*}{ No. of cases } & \multicolumn{6}{|c|}{ Lower limb level 1 mean CSA ( $\left.\mathrm{cm}^{2}\right)$} \\
\hline & & \multicolumn{2}{|c|}{ Right } & \multirow{2}{*}{$p$-value } & \multicolumn{2}{|c|}{ Left } & \multirow{2}{*}{$p$-value } \\
\hline & & Mean & SD & & Mean & SD & \\
\hline$<60$ & 61 & 0.426 & 0.025 & \multirow{3}{*}{$\begin{array}{l}r=0.905 \\
p=0.001\end{array}$} & 0.429 & 0.027 & \multirow{3}{*}{$\begin{array}{l}r=0.910 \\
p=0.001\end{array}$} \\
\hline $61-70$ & 64 & 0.498 & 0.032 & & 0.499 & 0.030 & \\
\hline$>70$ & 77 & 0.591 & 0.064 & & 0.593 & 0.064 & \\
\hline \multirow{3}{*}{ Weight (kg) } & \multirow{3}{*}{ No. of cases } & \multicolumn{6}{|c|}{ Lower limb level 2 mean CSA $\left(\mathrm{cm}^{2}\right)$} \\
\hline & & \multicolumn{2}{|c|}{ Right } & \multirow{2}{*}{$p$-value } & \multicolumn{2}{|c|}{ Left } & \multirow{2}{*}{$p$-value } \\
\hline & & Mean & SD & & Mean & SD & \\
\hline$<60$ & 61 & 0.321 & 0.027 & \multirow{3}{*}{$\begin{array}{l}r=0.817 \\
p=0.001\end{array}$} & 0.323 & 0.021 & \multirow{3}{*}{$\begin{array}{l}r=0.797 \\
p=0.001\end{array}$} \\
\hline $61-70$ & 64 & 0.386 & 0.040 & & 0.387 & 0.041 & \\
\hline$>70$ & 77 & 0.449 & 0.051 & & 0.445 & 0.054 & \\
\hline
\end{tabular}

Tab. 5. Cross-sectional area of the sciatic nerve at two levels and its relationship with BMI

\begin{tabular}{|c|c|c|c|c|c|c|c|}
\hline \multirow{3}{*}{ Body mass index } & \multirow{3}{*}{ No. of cases } & \multicolumn{6}{|c|}{ Lower limb level 1 mean CSA ( $\left.\mathrm{cm}^{2}\right)$} \\
\hline & & \multicolumn{2}{|c|}{ Right } & \multirow{2}{*}{$p$-value } & \multicolumn{2}{|c|}{ Left } & \multirow{2}{*}{$p$-value } \\
\hline & & Mean & SD & & Mean & SD & \\
\hline $19.5-22.5$ & 80 & 0.453 & 0.047 & \multirow{3}{*}{$\begin{array}{l}r=0.552 \\
p=0.001\end{array}$} & 0.458 & 0.053 & \multirow{3}{*}{$\begin{array}{l}r=0.487 \\
p=0.001\end{array}$} \\
\hline $22.6-24.5$ & 85 & 0.532 & 0.052 & & 0.531 & 0.051 & \\
\hline$>24.5$ & 37 & 0.593 & 0.105 & & 0.596 & 0.101 & \\
\hline \multirow{3}{*}{ Body mass index } & \multirow{3}{*}{ No. of cases } & \multicolumn{6}{|c|}{ Lower limb level 2 mean CSA $\left(\mathrm{cm}^{2}\right)$} \\
\hline & & \multicolumn{2}{|c|}{ Right } & \multirow{2}{*}{$p$-value } & \multicolumn{2}{|c|}{ Left } & \multirow{2}{*}{$p$-value } \\
\hline & & Mean & SD & & Mean & SD & \\
\hline $19.5-22.5$ & 80 & 0.343 & 0.041 & \multirow{3}{*}{$\begin{array}{l}r=0.560 \\
p=0.001\end{array}$} & 0.344 & 0.040 & \multirow{3}{*}{$\begin{array}{l}r=0.473 \\
p=0.001\end{array}$} \\
\hline $22.6-24.5$ & 85 & 0.415 & 0.046 & & 0.413 & 0.048 & \\
\hline$>24.5$ & 37 & 0.437 & 0.089 & & 0.433 & 0.085 & \\
\hline
\end{tabular}

Ricci et al. conducted a study involving ultrasound observations of the sciatic nerve and its branches at the popliteal fossa in normal subjects and in patients with venous disease. The sciatic nerve and its branches were visible and easily recognized in all the cases. The sciatic nerve and the small saphenous vein lay in close proximity in cases with small saphenous vein incompetence ${ }^{(17)}$. Vincent et al. conducted a study on the use of ultrasound in identifying the sciatic nerves at three locations in the lower extremity ${ }^{(18)}$. Similarly in our study, high-resolution ultrasonography was highly useful in tracing the course of the sciatic nerve in all the cases studied, and measuring the cross-sectional area accurately.

Chen et al. conducted a study based on high-resolution ultrasonography to establish the reference values for the cross-sectional area of the normal sciatic nerve in 200 healthy male or female volunteers, aged 18-80 years. Pearson's correlation analysis showed that the mean CSA of the sciatic nerve was positively correlated with subject height and weight. There was no difference in mean CSAs among the three age groups $(p>0.05)$. Women were found to have smaller CSAs of the normal sciatic nerves than men at two measuring sites $(p<0.05)^{(1)}$.

In the present study, the cross-sectional area of the sciatic nerve showed a positive correlation with the height and weight of the patients. The cross-sectional area of the sciatic nerve was found to be higher in men than in women. No significant relationship was established with the age of the subjects. The results of the present assessment are consistent with the findings of the study conducted by Chen et al. In our study, one additional parameter (BMI) was included. Similarly to the height and weight, the BMI also showed a positive correlation with the cross-sectional area.

High-resolution ultrasonography is an effective imaging technique that complements electrophysiological and other neuroimaging studies ${ }^{(4)}$. Lee et al. stated that highresolution ultrasonography plays a role in determining the correct diagnosis and location of lesions in all 13 cases included in the study. In 7 (58\%) out of 12 cases, highresolution ultrasonography provided the correct diagnosis when other imaging and electrophysiological studies were either inconclusive or inadequate ${ }^{(4)}$. Kerasnoudis et al. conducted a study in 75 healthy subjects to establish a relationship between cross-sectional area variability measured on high-resolution ultrasonography with pathological changes in the peripheral nerves. The CSA variability measures may be helpful in investigating the pathologies of the peripheral nerves $^{(3)}$. In our study, high-resolution ultrasonography provided the reference values of the normal cross-sectional area which aid in the early diagnosis of the sciatic nerve pathologies.

Qrimli et al. conducted a study in 100 healthy volunteers where the median, ulnar, fibular, tibial (branch of the sciatic nerve), sural and superficial fibular nerves at defined sites were focused with high-resolution ultrasonography. The cross-sectional area (CSA) values were measured in 
healthy subjects. The CSA tends to be bilaterally symmetrical in both lower limbs ${ }^{(5)}$. Also in our study, the cross-sectional area measures turned out to be symmetrical.

Kowalska et al. conducted a study in 47 patients aged 16-65 (mean age 33) who were referred to ultrasound examinations due to a clinical suspicion of posttraumatic peripheral neuropathies. The results of the clinical and surgical verification were consistent with the ultrasound findings in $100 \%$ of cases. The results showed that highresolution ultrasonography is a useful method in assessing patients for various types of treatment of peripheral neuropathies ${ }^{(19)}$. Likewise, in our study any change in the observed cross-sectional area helps in the identification of initial stages of peripheral neuropathies.

In the present study, high-resolution ultrasonography (5-18 MHz) was used to measure the cross-sectional area (CSA) of the normal sciatic nerve. It was clear that the CSA of the sciatic nerve was a more consistent measurement than the diameter. The results highlight the basic clinical applications of high-resolution ultrasonography for the future diagnosis, treatment, and prognostic evaluation of peripheral neuropathies.

\section{References}

1. Chen J, Liu J, Zeng J, Wu S, Ren J: Ultrasonic reference values for assessing normal sciatic nerve ultrasonography in the normal population. J Med Ultrasound 2018; 26: 85-89.

2. Rasenack M, Décard BF, Schädelin S Grimm A, Fischer D, Hafner P: Ultrasonographic reference values for peripheral nerves and nerve roots in the normal population of children and adolescents: study protocol for an observational-prospective trial. BMJ Open 2016; 6: e014662.

3. Kerasnoudis A, Pitarokoili K, Behrendt V, Gold R, Yoon M-S: Cross sectional area reference values for sonography of peripheral nerves and brachial plexus. Clin Neurophysiol 2013; 124: 1881-1888.

4. Lee FC, Singh H, Nazarian LN, Ratliff JK: High resolution ultrasonography in the diagnosis and intraoperative management of peripheral nerve lesions. J Neurosurg 2011; 114: 206-211.

5. Qrimli M, Ebadi H, Breiner A, Siddiqui H, Albdali M, Abraham A et al.: Reference values for high resolution ultrasonography of peripheral nerves. Muscle Nerve 2016; 53: 538-544.

6. Stacy MR, Dearth CL: Multimodelity imaging approaches for evaluating traumatic extremity injuries: implications for military medicine. Adv Wound Care (New Rochelle) 2017; 6: 241-251.

7. Kowalska B, Sudol-Szopińska I: Normal and sonographic anatomy of selected peripheral nerves. Part III: Peripheral nerves of lower limb. J Ultrason 2012; 12: 148-163.

8. Goedee HS, Brakelmans GJ, van Asseldonk JT, Beckman R, Mess WH, Visser LH: High resolution sonography in the evaluation of peripheral nervous system in polyneuropathy - a review of the literature. Eur J Neurol 2013; 20: 1342-1351.

9. Suk JI, Walker FO, Cartwright MS: Ultrasound of peripheral nerves. Curr Neurol Neurosci Rep 2013; 13: 328.
A limitation of the study is that the measurement of the cross-sectional area of the sciatic nerve was done only at two levels.

\section{Conclusions}

High-resolution ultrasonography allows direct imaging of the peripheral nerves including the sciatic nerve. It is a preferred technique, since it is easily accessible, noninvasive, and associated with a shorter examination time and lower costs. The proximal part of the normal sciatic nerve has a greater cross-sectional area, which decreases as the nerve courses distally. The reference values of the cross-sectional area of the sciatic nerve can facilitate the analysis of abnormal nerve conditions including peripheral neuropathies.

\section{Conflict of interest}

The authors do not report any financial or personal connections with other persons or organizations which might negatively affect the contents of this publication and/or claim authorship rights to this publication.

10. Lawande AD, Warrier SS, Joshi MS: Role of ultrasound in the evaluation of peripheral nerves. Indian J Radiol Imaging 2014; 24: 254-258.

11. Beltran LS, Bencardino J, Ghazikhanian V, Beltran J: Entrapment neuropathies III: lower limb. Semin Musculoskelt Radiol 2010; 14: 501-511.

12. Otani Y, Yermakov LM, Dupree JL, Susuki K: Chronic peripheral nerve compression disrupts paranodal axoglial junctions. Muscle Nerve 2017; 55: 544-554.

13. Hollister AM, Simoncini A, Sciuk A, Jordan J: High frequency ultrasound evaluation of traumatic peripheral nerve injuries. Neurol Res 2012; 34: 98-103.

14. Cartwright MS, Chloros GD, Walker FO, Wiesler ER, Campbell WW: Diagnostic ultrasound for nerve transection. Muscle Nerve 2007; 35: 796-799.

15. Koenig RW, Pedro MT, Heinen CPG, Schmidt T, Richter H-P, Antoniadis G et al.: High resolution ultrasonography in evaluating peripheral nerve entrapment and trauma. Neurosurg Focus 2009; 26: E13.

16. Garg K: Back of thigh. In: Garg K (ed.): Chaurasia's Human Anatomy Lower limb, Abdomen and Pelvis. Vol. 2, 4th ed. CBS Publishers and Distributors, New Delhi 2008: 91-101.

17. Ricci S: Ultrasound observation of the sciatic nerve and its branches at the popliteal fossa: always visible, never seen. Eur J Vasc Endovasc Surg 2005; 30: 659-663.

18. Chan VW, Nova H, Abbas S, McCartney CJ, Perlas A, Xu DQ: Ultrasound examination and localization of the sciatic nerve. Anesthesiology 2006; 5: 309-314.

19. Kowalska B: Assesment of the utility of ultrasonography with high frequency transducers in the diagnosis of post traumatic neuropathies. J Ultrason 2015; 15: 15-28. 